\title{
Medicina en Colombia. Profesión mediada por preceptos externos y prestigios internos (siglos XVIII al XX)*
}

\section{Resumen}

La medicina es la profesión que desde sus orígenes institucionales coloniales ha estado más regulada y supervisada en sus procesos de formación y ejercicio. A los controles de los Protomedicatos coloniales, las Academias científicas de la República y las Asociaciones de Facultades durante el siglo XX se han sumado las políticas públicas y los procesos universitarios de acreditación de los programas con los mejores criterios de alta calidad a inicios del siglo XXI. El artículo describe la historia de la medicina en Colombia planteando una perspectiva historiográfica alterna desde procesos de control y acreditación de la profesión mediados por preceptos y prácticas. Resultado de un proceso de investigación cualitativa, de carácter descriptivo, se revisan y contrastan diferentes fuentes que permiten indagar los procesos de titulación, corrientes historiográficas y fundamentos analíticos de la acreditación de las profesiones universitarias en salud que evidencian la continuidad de prácticas gremiales y concepciones bicentenarias.

\section{Palabras clave}

Tesauro: medicina, historiografía, profesión, acreditación, Colombia.

Referencia bibliográfica para citar este artículo: Pérez Pinzón, Luis Rubén. "Medicina en Colombia. Profesión mediada por preceptos externos y prestigios internos (siglos XVIII al XX)". Anuario de Historia Regional y de las Fronteras, 25.1 (2020): 205-221

Luis Rubén Pérez Pizón: Historiador de la Universidad Industrial de Santander. Docente investigador del Departamento de Estudios Sociohumanísticos de la Universidad Autónoma de Bucaramanga (Colombia). Código ORCID: 0000-0003-0387-6035. Correo electrónico: Lperez14@unab.edu.co

\footnotetext{
*Artículo resultante del proyecto de investigación interinstitucional titulado: "Contexto histórico de los programas de medicina en Colombia", reconocido y cofinanciado por la Universidad Autónoma de Bucaramanga (UNAB) con el código E89003 de 2018. La investigación contó con la participación de estudiantes-investigadores de la Facultad de Salud e integrantes del Semillero de Investigación en Literatura de la UNAB.
} 


\title{
Medicine in Colombia. Profession mediated by external precepts and internal prestige (eighteenth to twentieth centuries)
}

\begin{abstract}
Medicine is the profession whose training and practice processes have been more regulated and supervised since its colonial institutional origins. To the controls of the colonial protomedicates, the Scientific Academies of the Republic and the Associations of Faculties during the twentieth century, they were added public policies and university processes of accreditation with the best and highest quality at the beginning of the 21 st century. The article describes the history of medicine in Colombia, presenting an alternate historiographic perspective from processes of control and accreditation of the profession mediated by precepts and practices. This article is the result of a qualitative research process with a descriptive nature in which different sources are reviewed and contrasted. It allows to research the titling processes, historiographic currents and analytical foundations of the accreditation of professions in health which demonstrate continuity of association practices and bicentennial conceptions.
\end{abstract}

Keywords

Tesauro: medicine, historiography, profession, accreditation, Colombia.

\section{Medicina na Colômbia. Profissão mediada por preceitos externos e prestígios internos (séculos XVIII a XX)}

\begin{abstract}
Resumo
A medicina é a profissão que, desde suas origens institucionais coloniais, tem sido mais regulamentada e supervisionada em seus processos de treinamento $e$ exercício. Aos controles dos protomedicatos coloniais, as Academias Científicas da República e as Associações de Faculdades durante o século XX foram adicionadas políticas públicas e processos universitários de acreditação dos programas com os melhores critérios de alta qualidade no início do século XXI. O artigo descreve a história da medicina na Colombia, apresentando uma perspectiva historiográfica alternativa a partir de processos de controle e credenciamento da profissão mediada por preceitos e práticas. Este artigo é resultado de um processo de pesquisa qualitativa, de natureza descritiva, na qual são revisadas e contrastadas diferentes fontes que permitem pesquisar os processos de titulação, correntes historiográficas e fundamentos analiticos do credenciamento de profissões universitárias em saúde que demonstram continuidade de práticas de associações e concepções bicentenárias.
\end{abstract}

Palavras chave

Tesauro: medicina, historiografia, profissão, credenciamento, Colômbia. 


\section{Introducción}

La historiografía sobre el devenir de la medicina en Colombia, así como de campos de estudio complementarios a la misma como es el caso de la salud pública, la enfermedad, el sistema de salud, etc., ha cambiado a la par de las variaciones en las tendencias, modelos y representaciones acerca de la historia médica del país. Una perspectiva académica o positivista de estudio ha estado centrada en los metarelatos a los cambios en las políticas médicas y las gestas de los médicos más afamados. En contraposición a esa tendencia, algunos estudios universitarios centran sus análisis en los paradigmas científicos que propiciaron los cambios políticos e institucionales del hacer médico. Así mismo, las recurrentes necesidades de reconocimiento, conmemoración y acreditación interinstitucional han propiciado una tercera opción asociada al microrelato institucional sobre la formación de los médicos y el ejercicio de la medicina.

La tradición positivista de las Academias de Historia, así como los esfuerzos de organizaciones estamentales como la Academia de Ciencias o la Academia de Medicina, se ha caracterizado por compilar acervos documentales que describen la historia de la medicina en Colombia como reflejo de los cambios del sistema político dominante y el heroísmo administrativo o profesional de los médicos más destacados. Esos estudios, en su mayoría de médicos-historiadores sobre médicos-históricos, dividen las gestas de la medicina en Colombia acorde a los períodos prehispánico, colonial, republicano y ministerial. ${ }^{1}$ De esa corriente son los relatos de Pedro Ibáñez, Emilio Robledo, Andrés Soriano, Virginia Gutiérrez, Rafael Martínez, Hugo Sotomayor, Juan Pinzón, Roberto Serpa, Fernando Serpa, Roberto de Zubiria, entre otros.

La perspectiva crítica a esa interpretación cronológica e institucional de la historia han sido los estudios consecuentes al impacto de la "Nueva Historia", promovida desde las facultades universitarias en ciencias humanas y sociales por los historiadores profesionales. Las investigaciones científicas han optado por dar prioridad a las causas y efectos de los grandes paradigmas de estudio y ejercicio de la medicina en Colombia como han sido los paradigmas: etnobotánico de la Expedición Botánica, el sistémico y anatoma-patológico de las universidades capitalinas, el higienista regenerador, así como el flexneriano, adoptado desde mediados del siglo XX. ${ }^{2}$ A los estudios pioneros de Emilio Quevedo y Néstor Miranda, inscritos en la visión de una historia de las ciencias y las profesiones en Colombia, se suman las investigaciones que recrean los paradigmas o escuelas de pensamiento dominantes en la medicina nacional como son los trabajos de grado de Adriana Alzate, ${ }^{3}$ Diana

\footnotetext{
${ }^{1}$ Emilio Quevedo, Historia de la medicina en Colombia. (Bogotá: Grupo Editorial Norma, 2007), 5.

${ }^{2}$ Néstor Miranda Canal, «Apuntes para la historia de la medicina en Colombia». Ciencia, Tecnología y Desarrollo. Bogotá Vol. 8, No. 1-4 (1984): 136-147

${ }^{3}$ Adriana Alzate, Los oficios médicos del sabio: contribución al estudio del pensamiento higienista de José Celestino Mutis. (Medellín: Universidad de Antioquia, 1999).
} 
Medicina en Colombia. Profesión mediada por preceptos externos y prestigios internos...

Obregón, ${ }^{4}$ Abel Martínez, ${ }^{5}$ Carlos Noguera, ${ }^{6}$ Mónica García, ${ }^{7}$ entre otros. Sin olvidar trabajos pioneros sobre el contraste entre las nuevas teorías científicas externas y los cambios en las prácticas médicas internas como el de Alfonso Bonilla. ${ }^{8}$

Conjugando los factores externos que limitaban la formación y el ejercicio médicos con las tendencias y concepciones internas sobre el hacer y el ser del médico, una tercera perspectiva analítica ha estado influenciada por las discusiones internacionales sobre cómo abordar y proyectar los estudios retrospectivos sobre las profesiones asociadas con la salud pública. Lo cual implica integrar las profesiones y ciencias auxiliares de la medicina con las ciencias sociales y humanas que estudian las causas de los problemas ambientales y patológicos de las sociedades en su afán de alcanzar condiciones integrales de salud y bienestar.

En el caso particular de los estudios científicos en historia de la salud, la medicina y la enfermedad promovidos desde la Escuela de Historia de la Universidad Industrial de Santander, ha sido analizado el devenir de los cambios intrainstitucionales de la medicina para afrontar los problemas sanitarios de mayor impacto para el país. ${ }^{9}$ Con lo cual, el interés de los médicos y hospitales coloniales por erradicar la viruela y el coto fue reorientado a la curación de la lepra y los ciclos de viruela durante el siglo XIX, ${ }^{10}$ y posteriormente a la prevención de epidemias como la fiebre amarilla, sífilis, tuberculosis y enfermedades mentales durante el siglo XX. A lo cual, se han sumado los esfuerzos por contrarrestar los efectos del cáncer y el sida durante el primer cuarto del siglo XXI. ${ }^{11}$

Desde ese contexto de representaciones paralelas sobre la historia de la medicina en Colombia, las siguientes secciones describen cómo la producción historiográfica suele diferenciar y contraponer las perspectivas heroicas de los médicos-historiadores adscritos a las academias de historia (primera sección) de las investigaciones sistémicas de los historiadores-profesionales adscritos a grupos y centros investigación interesados en los imaginarios científicos de los médicos

${ }^{4}$ Diana Obregón, Batallas contra la lepra: estado, medicina y ciencias en Colombia. (Bogotá: Banco de la República, 2002).

${ }^{5}$ Abel Martínez, El Lazareto de Boyacá: lepra, medicina, iglesia y estado 1869-1916, (Tunja: Universidad Pedagógica y Tecnológica de Colombia, 2006).

${ }^{6}$ Carlos Noguera, Medicina y politica: discurso médico y prácticas higiénicas durante la primera mitad del siglo XX en Colombia, (Medellín: Eafit, 2003).

${ }^{7}$ Mónica García, Entre climas y bacterias: el saber sobre la enfermedad en Colombia, siglo XIX (Bogotá: Universidad del Rosario, 2016).

${ }^{8}$ Alfonso Bonilla Naar, Historia de la medicina tropical: parasitología e higiene en Colombia, datos bibliográficos correspondientes a 113 años de labores colombianas (1830-1943) (Bogotá: Cromos, 1944).

${ }^{9}$ Luis Rubén Pérez Pinzón, Historia de la Salubridad en Santander. (Bucaramanga: Luis Pérez, 2015), 3 t.

${ }^{10}$ Luis Rubén Pérez Pinzón, «La lepra y los lazaretos en Santander. Discapacidad clínico-hospitalaria y minusvalía socio-cultural». Revista Salud UIS Vol. 37, No. 3 (2005):141-151.

${ }^{11}$ Luis Rubén Pérez Pinzón, ed. Beneficencia, Higiene y Salud Pública en Colombia: La experiencia médico-sanitaria en Santander. Siglos XIX y XX. Trabajos de grado de la Escuela de Historia de la Universidad Industrial de Santander asociados con la línea de investigación en Historia de la Salud Pública y la enfermedad. (Bucaramanga: UIS, 2013). 
(segunda sección). Lo cual se refleja en la polaridad de los contenidos y la bibliografía que considerada para el diseño y realización de cursos universitarios en historia de la medicina. En alternancia a esas perspectivas de análisis, en la tercera sección es propuesto otro enfoque de análisis sobre el devenir de la medicina en Colombia desde los procesos gremiales de acreditación y licenciamiento estatales que han propiciado el rescate, la compilación y divulgación de relatos históricos institucionales, desde los intereses específicos de los médicos. ${ }^{12}$

\section{La historia de la medicina limitada por los preceptos e interpretaciones externas}

Tradicionalmente se ha asumido que cada régimen sociopolítico ha tenido sus propias prácticas médicas al relacionarse el período precolombino con los conocimientos botánicos de los sacerdotes indígenas, el período colonial con el conocimiento farmacéutico de algunos sacerdotes católicos que ejercían como médicos personales o locales y el período republicano con el ejercicio de la medicina por parte de médicos titulados en hospitales públicos y especializados en universidades europeas. ${ }^{13}$ El período de entreguerras mundiales propició a su vez el fomento de una medicina científica, institucionalizada y estatizada, cuyas prácticas fueron transformadas con la apertura de mercados y la privatización de los servicios en salud como efecto de las reformas de gobiernos neoliberales. ${ }^{14}$

Desde la perspectiva de las influencias externas, se ha explicado el cambio de las prácticas médicas como reflejo de los cambios en los paradigmas y corrientes científicas del ejercicio profesional. Las prácticas etnobotánicas del chamanismo que regulaba los regímenes cacicales fueron sustituidas por las concepciones hipocráticas del colonialismo hispano-católico. La búsqueda de una identidad nacional republicana, paralela al reconocimiento internacional por otras naciones "progresistas", propiciaron la continuidad de las reformas mecanicistas de los virreyes borbones, el afrancesamiento de los hospitales de caridad como campos de formación médica, la adopción del sistema británico para el manejo de los hospitales de leprosos, ${ }^{15}$ así como los primeros republicanos sensualistas y pragmáticos propiciaron la sustitución de la educación tomista dominante al contratar misiones de catedráticos franceses y alemanes.

Ese enciclopedismo racionalista fue a su vez superado por el empirismo positivista y utilitarista de los reformadores republicanos, influenciados por los avances científicos de Francia e Inglaterra, quienes al retornar de Paris lideraron la creación de la primera escuela privada, la primera revista científica y la primera facultad pública,

\footnotetext{
${ }^{12}$ Universidad Autónoma de Bucaramanga. Proyecto de investigación E89003: Contexto histórico de los programas de Medicina en Colombia. (Bucaramanga: Universidad Autónoma de Bucaramanga, 2019).

${ }^{13}$ Pedro Ibáñez, Memorias para la historia de la medicina en Santa Fé de Bogotá (Bogotá: Universidad Nacional de Colombia, 1967).

${ }^{14}$ Quevedo, Historia...

${ }^{15}$ Pérez, Beneficencia...
} 
mediadas por la formación obtenida en laboratorios de experimentación. Prácticas científicas mediadas por la técnica y la tecnología que facilitaron la adopción y acoplamiento a las innovaciones de la medicina norteamericana, ${ }^{16}$ centrada en el estudio riguroso de las enfermedades tropicales en laboratorios controlados, la adopción de procedimientos técnicos rigurosos durante la atención hospitalaria y la mediación de máquinas sofisticadas para el diagnóstico especializado y el tratamiento sistemático de las enfermedades. ${ }^{17}$

La interpretación social del ejercicio profesional de la medicina ha propuesto, por el contrario, una revisión de los procesos internos de cambio y adaptación de las tendencias externas desde las "mentalidades médicas". El papel que tuvieron los sabios de los siglos XVII y XVIII en el monopolio de la patología y terapéutica de las enfermedades, acorde a las observaciones, hallazgos o invenciones que realizaban de forma cerrada con sus cátedras, expediciones, prácticas o experimentos que demostraban el "desequilibrio de los humores" y las causas ambientales de las enfermedades (mentalidad sistémica), fue sustituida por la institucionalización de centros de formación universitaria de carácter abierto. Lugares donde primaba la apropiación de las obras científicas y los métodos de formación aplicada promovidos por los médicos más destacados de Francia, Inglaterra y Alemania, interesados en el desequilibrio de las excitaciones anatómicas (mentalidad neo-sistémica). ${ }^{18}$

Las particularidades de las enfermedades, la terapéutica y el ejercicio de la profesión médica en Colombia conllevaron a la búsqueda de un pensamiento y ejercicio médico específico para el país, para conformar una "patología nacional"19 caracterizada por: la agremiación de un cuerpo médico interesado en la formación científica de sus colegas; la concentración de la formación y la investigación médica en una universidad que representara a la nación con becados provenientes de todos los territorios, quienes debían retornar y ejercer su profesión en las provincias de origen; la creación o de adecuación de los establecimientos hospitalarios con la pretensión de realizar experimentos científicos (mentalidad anatomo-clínica); la búsqueda de soluciones propias a los problemas nacionales apelando a la experticia e investigación en los laboratorios de médicos nacionales (mentalidad fisio-etiopatológica), y consigo, la divulgación internacional de los hallazgos nacionales por medio de publicaciones científicas. $^{20}$

La transición de las mentalidades médicas conllevó al reconocimiento de otra periodicidad paralela a las mismas, asociada con la dependencia médica del país. La sustitución de la tradición hipocrática que caracterizaba la práctica médica

\footnotetext{
${ }^{16}$ Quevedo, Historia...

${ }^{17}$ Néstor Miranda Canal, «La medicina en Colombia. De la influencia francesa a la norteamericana». Credencial Historia, 1992, http://www.banrepcultural.org/biblioteca-virtual/credencial-historia/ numero-29/la-medicina-en-colombia

${ }^{18}$ Miranda, Apuntes...

${ }^{19}$ Miranda, La medicina...

${ }^{20}$ Miranda, Apuntes...
} 
neogranadina estuvo asociada con el fomento de la ilustración española por sabios pioneros como José Celestino Mutis. Personaje pionero del saber médico moderno quien a la par de impulsar cátedras médicas y practicas novedosas en cirugía y farmacia reafirmó su posición dominante a través del corporativismo de su expedición botánica, la lealtad de sus discípulos herederos de las cátedras en medicina y el absolutismo "entre sabios" que ejercía con los mismos a través del protomedicato de Santafé. ${ }^{21}$

Con la muerte de J. Mutis y la de sus leales seguidores fue promovido el aprendizaje del positivismo médico francés, especialmente desde la difusión y aceptación de la obra de François Broussais, por una nueva generación de médicos catedráticos formados y contratados en Europa para las nacientes universidades colombianas. Período que desde mediados del siglo XVIII hasta mediados del siglo XIX evidenció la dependencia y ciega apropiación de los saberes empíricos y las prácticas médicas europeas, especialmente la francesa. Y, por ende, el reconocimiento de una forma consecutiva de "medicina en Colombia", ${ }^{22}$ que imponiendo los preceptos externos coexistía con prácticas médicas etnobotánicas, populares o alternativas.

La búsqueda de soluciones propias a los problemas médicos nacionales por médicos formados y altamente comprometidos con la explicación y solución a las enfermedades endógenas conllevó al uso de laboratorios, a la adaptación de las teorías organicistas y bacteriológicas, la atención y prevención de los factores de riesgo, y consigo, a la gradual constitución de una "medicina de Colombia". ${ }^{23} \mathrm{La}$ cual se emancipó gradualmente de las corrientes francesas tradicionales y optó, un siglo después de adoptar plenamente la medicina francesa anatomoclínica, por las prácticas interdisciplinarias de la medicina norteamericana desde la perspectiva de la tecnología sanitaria, un modelo eficiente de salud pública influenciado por el sistema inglés y el fortalecimiento de prácticas médicas regionales a la usanza alemana.

Las periodizaciones cronológicas, externalistas, de las mentalidades y de la dependencia implícitamente contienen una temporalidad adicional, asociada con los procesos de organización gremial del cuerpo médico. Al corporativismo que J. Mutis y los sabios ilustrados promovieron a través de la Expedición Botánica, el Tribunal del Protomedicato y la Sociedad de Amigos para salvaguardar sus intereses y prerrogativas, se sumaron las agremiaciones promotoras de la medicina y las grandes obras de la medicina francesa e inglesa al interior de los claustros académicos capitalinos, cuya influencia cesó al decretarse a mediados del siglo XIX el libre ejercicio de las profesionalizaciones, sin condicionamientos a la presentación o regulación de títulos universitarios, excepto el oficio de farmaceuta.

Los médicos titulados ante esa alteración de su condición preferencial y los graves males que se ocasionaban a la sociedad con medicamentos y terapias contraproducentes defendieron su condición legal como profesionales con licencia

\footnotetext{
${ }^{21}$ Ibáñez, Memorias...

${ }^{22}$ Miranda, Apuntes..., 134

${ }^{23}$ Miranda, Apuntes..., 133
} 
y privilegio para ejercer su saber al organizar una sociedad médica excluyente, una escuela de medicina profesional y una publicación científica nacional. Las cuales sentaron los orígenes de la facultad de medicina de la Universidad Nacional y sus homologas departamentales, y cien años después, la creación de la Asociación Colombiana de Facultades de Medicina (Ascofame). Ejemplo de esa historiografía de periodizaciones institucionales son las obras de Roberto Serpa-Flórez ${ }^{24}$ para el caso de Santander.

Ascofame como agremiación privada ha contribuido en la defensa de la condición legal de los pregrados, facultades y universidades autorizadas para impartir títulos de medicina, y consigo, solo ha permitido la afiliación a las carreras de medicina que concurrieron a su constitución como fundadoras, las que son aceptadas (acreditadas o no) al cumplir los estatutos, así como aquellas que sean aceptadas por la Asamblea General. De tal modo, el objeto principal de Ascofame: “[...] es velar y propender por la calidad de la educación médica colombiana y su impacto en la salud en general". ${ }^{25}$

\section{La profesión médica concebida por los médicos, pero regulada por el Estado}

La medicina ha sido definida en Colombia, desde 1962, como el ejercicio profesional caracterizado por: “[...] La aplicación de medios y conocimientos para el examen, diagnóstico, prevención, tratamiento y curación de las enfermedades, así como para la rehabilitación de las ciencias o defectos ya sean físicos, mentales o de otro orden que afecten a las personas o que se relacionen con su desarrollo y bienestar". ${ }^{26}$ La Ley 14 de 1962 derogó y reformó la Ley 67 de 1935 por medio de la cual se habían hecho ajustes legales y constitucionales al ejercicio de la profesión de la medicina y la cirugía intervenida en el último cuarto del siglo XIX. Siendo complementada esa normatividad por la Ley 1164 del 2007.

Acorde a la tradición de las dignidades y privilegios en los oficios, heredada y exigida por médico prestigiosos del período colonial como José Celestino Mutis o Miguel de Isla, el ejercicio profesional de la medicina solo lo han podido realizar quienes obtengan el título de médico y cirujano, expedido por una facultad o escuela universitaria reconocida por el Estado, que funcionen o hayan funcionado legalmente en el país y, que sus títulos como sus planes de estudios sean aprobados por una agremiación medica previamente autorizada por el Estado. Para lo cual, en la colonia estaban los Protomedicatos, durante la República bipartidista las Academias de Ciencias y con la república pluripartidista con la Asociación Colombiana de Facultades de Medicina. Hoy, los títulos expedidos por las universidades o escuelas deben ser

\footnotetext{
${ }^{24}$ Roberto Serpa-Flórez, “Apuntes para la historia de la medicina. Santander y la UIS”. Médicas UIS Revista de los estudiantes de medicina de la Universidad Industrial de Santander, Vol, 20, No. 2 (2007): 157-167

${ }^{25}$ Diego Giraldo, Memorias para la historia de la Asociación Colombiana de Facultades de Medicina Ascofame. (Bogotá: Ascofame, 2009), 2

${ }^{26}$ República de Colombia, Ley 14 de 1962 (abril 28) por la cual se dictan normas relativas al ejercicio de la medicina y cirugía. Art. 1. https://www.mineducacion.gov.co/1621/articles-103807 archivo_pdf.pdf
} 
validados ante las Secretarías Departamentales de Salud, antes que el Ministerio de Educación Nacional refrende el título y el Ministerio de Salud Pública autorice el ejercicio profesional del titulado. ${ }^{27}$

Esa estructura vertical, jerarquizada e interinstitucional de formación y otorgamiento de títulos a partir de la aprobación de las cátedras universitarias para cada año de formación del médico-cirujano neogranadino fue concebida y promovida desde finales del siglo XVIII por J. Mutis ante la carencia de médicos hábiles y las luchas de poder entre los protomedicatos de Santafé y Cartagena. Considerando las innovaciones universitarias que se promovían en Cádiz como en Madrid, Mutis propuso a la Corona reestablecer y asegurar los recursos para cursar la cátedra de Medicina en los colegios y la universidad capitalina acorde al siguiente plan:

[...] Tratándose de criar médicos y cirujanos patricios bien instruidos, y en número suficiente para llenar de pronto el inmenso vacío de las primeras poblaciones del Reyno; y perpetuar sucesivamente la enseñanza de modo que dentro de pocos años se pueda propagar el mismo beneficio a las menores poblaciones a imitación de lo que se practica en Europa, es necesario fijar un establecimiento permanente de cátedras, cuyo número, dotación, ramos de enseñanza y maestros puedan verificarse prontamente según las actuales proporciones, y por unos tan fáciles arbitrios, que excluyan absolutamente las invencibles dificultades de los proyectados por Burdallo y los médicos informantes. Bastan por ahora las ocho cátedras de primer establecimiento permanente y siempre fijas en lo sucesivo, sin exclusión de otras dos o tres que se podrán fundar en adelante con el fin de ampliar la enseñanza de los conocimientos auxiliares y relativos a la salud pública. ${ }^{28}$

Apelando al espíritu plural de la Constitución de 1991, la Ley 14 de 1962 fue demanda por inconstitucional en 1994 al considerar los chamanes, curanderos, teguas, brujos y demás sanadores tradicionales que no necesitaban título ni licencia para ejercer la medicina y cirugía como médicos empíricos. ${ }^{29}$ En respuesta a esa pretensión, la Corte Constitucional reconoció que la existencia de médicos profesionales era una de las tareas reguladoras del Estado para preservar la vida y la salud de cada comunidad de ciudadanos, a partir de los avances certificados de la ciencia y el conocimiento, antes que la tradición de una cultura étnica o de creencias populares. ${ }^{30}$

Situación semejante se había presentado a mitad del siglo XIX, donde a la par de separar la Iglesia del Estado, se ordenó la separación del oficio de la academia al promoverse y decretarse la libertad de enseñanza y ejercicio de profesiones, incluido el de la medicina. La Ley del 15 de mayo de 1850, en su afán de promover la libertad de enseñanza plena decretó suprimir las escuelas y universidades del país que regulaban

\footnotetext{
${ }^{27}$ República Art. 2 y 3.

${ }^{28}$ José Celestino Mutis, "Copia del Informe sobre el estado de la medicina, cirugía y farmacia del Nuevo Reino de Granada”, Santafé, 3 de junio de 1801. Biblioteca Nacional de Colombia, folio 101v.

${ }^{29}$ Juan Garzón, Etnodesarrollo y medicina indígena ecológica, (Bogotá: Ministerio de Salud, 1980).

${ }^{30}$ Corte Constitucional de Colombia, Expediente D-486, Sentencia C-377/94 que declara exequible la ley 14 de 1962. Parte I. http://www.secretariasenado.gov.co/senado/basedoc/c-377 1994.html
} 
y limitaban la vida académica de los ciudadanos. Y consigo, el presidente José Hilario López expidió la resolución del 19 de agosto de 1853 mediante la cual se fijó la fecha de suspensión y desconocimiento de toda expedición de títulos universitarios. Con lo cual, se asumió que para ejercer una actividad útil no se requería ostentar o demostrar un grado o título académico para ejercer las profesiones liberales o científicas.

Esa situación obligó a los médicos no titulados y a los catedráticos a cargo de los estudiantes de último año, como fue el caso del médico Antonio Vargas Reyes, a graduarlos y titularlos en el menor tiempo posible para validar sus estudios, y en lo posible ejercer o continuar su formación fuera del país. Acorde al testimonio del médico Justiniano Montoya:

[...] como los liberales se habían apoderado del gobierno, resolvieron suprimir los grados científicos y universitarios. Fijaron con mucha anticipación, que el día primero de septiembre de 1853, en adelante no se concedería más grados. Con este motivo todos los jóvenes aprovechados que estaban estudiando, redoblaron sus estudios y noche y día trabajaron sin descanso para poder presentar sus exámenes y obtener sus grados antes de aquel día. ${ }^{31}$

Liberalidad que no se repitió en 1994. Por el contrario, fue unánime el consenso de las cortes del estado al solicitar negar la impugnación de los médicos empíricos y mantener exequible la ley de 1962 ante la Constitución de 1991, al ser obligación de los poderes del Estado: “[...] reivindicar la facultad constitucional que tiene el Estado para regular y reglamentar la práctica de la medicina conforme a los criterios de idoneidad fijados por la ley". ${ }^{32}$ Así, al ser los títulos regulados por el Estado y la práctica final una condición necesaria para poder ejercer la profesión, la principal variación durante doscientos años han sido los enfoques científicos y clínicos que han orientado la formación médica. Es decir, durante el período colonial imperaron los planes de estudio guiados por las enseñanzas hipocráticas, durante la primera mitad del siglo XIX por la corriente médica francesa anatomo-clínica, durante la segunda mitad del siglo XIX por la corriente médica francesa fisio-etio-patológica y desde mediados del siglo XX por la corriente médica y sanitaria estadounidense, regulada por el modelo flexneriano. ${ }^{33}$

Esa dependencia epistemológica, clínica y científica de los grandes centros de desarrollo médico del mundo hicieron que, hasta hace muy poco, los programas de formación del país lograran pasar de "la medicina en Colombia" a promover la "medicina de Colombia". Y en el mejor de los casos, una "medicina colombiana"34 al lograrse avances de interés global como la válvula de Hakim, las innovaciones genéticas de Yunis, el método madre canguro, el marcapasos de Reynolds, la vacuna de Patarroyo o las zonas francas de turismo médico. ${ }^{35}$

\footnotetext{
${ }^{31}$ Roberto de Zubiría. Antonio Vargas Reyes y la Medicina del Siglo XIX en Colombia. (Bogotá: Academia Nacional de Medicina, 2002), 66.

${ }^{32}$ Corte I.

${ }^{33}$ Quevedo.

${ }^{34}$ Miranda.

${ }^{35}$ Mónica Vargas-Mantilla, "Revisión de estrategias de turismo de salud e identificación de aportes para Santander, Colombia”, MedUNAB, Vol. 20, No. 3 (2017-2018):349-361.
} 


\section{La historia de la medicina desde el reconocimiento y la credibilidad interinstitucional}

Durante el período colonial, las únicas instituciones autorizadas para enseñar y expedir títulos en medicina eran las facultades mayores de los colegios santafereños, reconocidas y reguladas por el gobierno virreinal a través de los protomedicatos y la universidad dominica. Durante el período republicano, esa atribución recayó en los gobiernos presidenciales al tener la facultad de crear o extinguir los programas y facultades de medicina existentes en las universidades centrales. ${ }^{36}$ La crisis en los procesos de regulación estatal de la formación y el ejercicio de la medicina acontecido a mediados del siglo XIX propició la reacción de los catedráticos universitarios y los médicos especializados en el exterior al ofertar servicios científicos certificados entre las familias privilegiadas y sus clientelas laborales, así como garantizaron la formación profesional de médicos al crear la Academia (privada) de Medicina.

La presión gremial de los profesionales pertenecientes a las elites capitalinas provinciales, las faltas éticas y los errores hospitalarios de los médicos "matasanos", así como el horror que causaba el incremento de muertos y secuelas físicas entre los enfermos de lepra y viruela, hicieron necesario regenerar y restaurar la regulación de la calidad y experticia de los médicos titulados al articularse los esfuerzos de la Academia Nacional a la naciente Facultad de Medicina de la Universidad Nacional de Colombia. Posteriormente, fueron reestablecidos por el Ministerio de Instrucción los planes de estudio y los requisitos formativos para la titulación y ejercicio de los profesionales de las facultades de medicina, tanto capitalinas como departamentales. ${ }^{37}$

Esas pautas de regulación y credibilidad cambiaron a mediados del siglo XX con la adopción de parámetros internacionales de reconocimiento y acreditación de la calidad de la medicina y los médicos, lo cual ha propiciado una perspectiva alternativa para la historia de la medicina en Colombia al repensarse desde el papel de las agremiaciones médicas y el prestigio interinstitucional como aspectos condicionantes y reguladores de los cambios médicos del país. Razón por la cual, cada universidad, facultad o programa de medicina han optado por configurar un relato histórico y una revisión historiográfica acorde a los imaginarios intrainstitucionales sobre su devenir, así como para evidenciar ante los evaluadores nacionales o internacionales los preceptos, regulaciones y proyecciones sobre el ser y el hacer de la profesión médica y sus especialidades. Ejemplo de ello es el estudio de Jairo Tellez ${ }^{38}$ sobre la toxicología desde las articulaciones, innovaciones y aportes de una institución en contaste con las demás universidades.

Tal perspectiva sobre el reconocimiento externo y la credibilidad interna entre universidades se originó con la visión médica norteamericana consecuente al

\footnotetext{
${ }^{36}$ Ibáñez, Memorias...Cap. IV.

${ }^{37}$ Pérez, Proyecto...

38 Jairo Téllez, Maestría en toxicología: Once años de historia. (Bogotá: Universidad Nacional de Colombia, 2011).
} 
"Informe Flexner" (1910) de Abraham Flexner, el cual fue adoptado formalmente en el país al acatarse las recomendaciones hechas por la Misión Médica Unitaria del Unitarian Service Committe (1948), dirigida por G. Humphreys como jefe del Colegio de Médicos y cirujanos de la Universidad de Columbia (Misión Humphreys). Aunado al modelo sanitario recomendado por la Asociación Médica Americana a la Academia Nacional de Medicina, como su homóloga en Colombia y principal asesora del Gobierno Nacional. Los efectos a corto plazo de esas inherencias sanitarias fueron la modificación de la política pública de salud y el enfoque médico francés por el norteamericano al pasarse de un Ministerio de Higiene (1946) a un Ministerio de Salud Pública (1956). ${ }^{39}$

La proyección de la medicina como una actividad gremial especializada y organizada ha conllevado además a replantear las perspectivas de estudio acerca de su pasado como un gremio que ha afrontado desde sus propias particularidades y luchas internas las reformas a los sistemas de salud y las cambiantes exigencias del sistema educativo. Rememorando para tal fin, momentos trascendentales para la historia del reconocimiento y la credibilidad gremial como fueron la descentralización de los títulos y profesiones a mitad del siglo $\mathrm{XIX}^{40} \mathrm{o}$ la centralización de la seguridad social a mediados del siglo XX. ${ }^{41}$ De allí que Ascofame formalizara ese espíritu corporativo al convocar a las facultades de medicina de: las dos universidades rivales desde el período colonial en Bogotá; las cuatro universidades departamentales que representaban la pluralidad formativa y de necesidades médicas nacionales; la facultad de la Universidad de Cartagena reorganizada en 1959, después de su inexistencia ininterrumpida desde 1830, así como la facultad de medicina creada en el Colegio Mayor del Rosario (1653) al representar a la Sociedad de Cirugía de Bogotá y su labor en el hospital de San José. Dando cuenta de esas gestiones y cambios gremiales en una obra histórica conmemorativa publicada con el título: "Memorias para la historia de la Asociación Colombiana de Facultades de Medicina Ascofame". ${ }^{2}$

Consecuente al cambio de Constitución en 1991 y la adopción de una ley orgánica para reorganizar el servicio público de la educación superior fue establecido el Consejo Nacional de Acreditación (CNA) con el propósito de unificar y articular una política pública para la regulación, certificación y acreditación de la calidad de los programas profesionales en Colombia. Así como en el siglo XVIII el Protomedicato de Santafé fue la institución reguladora del ejercicio y la formación médica, en el siglo XIX la Academia de Medicina y desde mediados del siglo XX lo fue Ascofame, el CNA por mandato de la Ley General de Educación Superior (Ley 30 de 1992) se constituyó desde finales de 1994 en el organismo estatal, dependiente del Consejo Nacional de Educación Superior, encargado de la "[...] coordinación, planificación,

\footnotetext{
39 José Patiño, "Abraham Flexner y el Flexnerismo. Fundamento imperecedero de la Educación Médica Moderna”, Revista de la Academia Nacional de Medicina Colombia, Vol 20, No. 2 (1998): 6-14.

${ }^{40}$ Universidad Autónoma, Proyecto de investigación E8900.

${ }^{41}$ Luis Rubén Pérez Pinzón, "La salud pública en Santander. Historias e historiadores". MedUNAB. Revista de la Facultad de Ciencias de la Salud, Vol. 11, No. 2. (2008): 124-139.

${ }^{42}$ Giraldo, Memorias...,91.
} 
recomendación y asesoría en el tema de acreditación de programas y de instituciones de Educación Superior en Colombia". ${ }^{33}$

Ese accionar de los pares evaluadores que en representación de otras facultades de medicina acreditadas en el país y en nombre del CNA analizan el devenir de los programas de medicina evaluados y sus proyecciones acordes a las políticas gremiales e interinstitucionales, han conllevado a que cada facultad reconsidere y reescriba el discurso histórico de sus orígenes y el devenir de su misión formativa desde la perspectiva de los procesos históricos de articulación nacional y cooperación internacional, antes que desde las representaciones dominantes sobre el heroísmo médico o los discursos científicos que han caracterizado la historia de la medicina realizada por historiadores externos o independientes.

Ejemplo de ello son las recientes investigaciones sobre facultades o programas específicos de medicina con fines de acreditación y como muestra de los cambios y particularidades de la compleja historia nacional de una profesión repensada internamente para dar respuesta a los procesos de reconocimiento estatal mediados por la visibilidad social y la credibilidad gremial. Siendo de resaltar historias institucionales recientes sobre las facultades de medicina de la Universidad de Antioquia, ${ }^{44}$ la Universidad Javeriana ${ }^{45}$ y la Universidad Nacional de Colombia. ${ }^{46}$

Los médicos-autores de la historia de la facultad de medicina de la Universidad Javeriana, pensando específicamente en procesos de acreditación nacionales e internacionales y sin renunciar a las historias de grandes médicos e imaginarios gremiales, dividen la estructura de la obra en las tres funciones misionales de todo programa universitario como son: educación médica (pregrado, posgrado, departamentos, profesores, convenios y espacios académicos, estudiantes, escenarios de práctica como servicio), investigación médica (trabajos de grado, departamentos e institutos, grupos y semilleros, redes de investigación, revistas), extensión y proyección (medio universitario, educación continuada, movilidad y grupos estudiantiles). Siendo reafirmada la "identidad y sueños" asociados con la facultad de medicina al rememorar en un primer capítulo la primera cátedra, biblioteca y facultad médica de los jesuitas (1683), así como en cada uno de los capítulos es redactada una sección sobre los médicos considerados "javerianos memorables". ${ }^{47}$

\footnotetext{
${ }^{43}$ Consejo Nacional de Acreditación (CNA), Conozca el CNA, https://www.cna.gov.co/1741/article-186382. html.

${ }^{44}$ Tiberio Álvarez, Escuela de medicina de la Universidad de Antioquia: ciencia y presencia en la historia, 1871-2016, (Medellín: Universidad de Antioquia, 2017).

45 Pontificia Universidad Javeriana, Facultad de medicina 75 años entregando el corazón, (Bogotá: Universidad Javeriana, 2017).

${ }^{46}$ Juan Eslava, Facultad de medicina: su historia,. (Bogotá: Universidad Nacional de Colombia, 2018). 2 v.

${ }^{47}$ Pontificia, Facultad..., 6-8.
} 


\section{Conclusión}

A la par de los estudios históricos que centran su interés sobre la historia de la medicina en Colombia considerando factores políticos y hazañas personales para explicar los cambios organizacionales, así como las investigaciones científicas que promueven la correlación entre las innovaciones científicas y los cambios en las prácticas institucionales y los procesos de formación médica ante los grandes problemas higiénicos del país, desde la perspectiva salubrista de los gremios y asociaciones médicas ha sido fomentada una tercera perspectiva investigativa centrada en los cambiantes procesos de regulación y reconocimiento de la calidad, credibilidad y prestigio de los programas de medicina desde la construcción de sus propios discursos históricos.

La historia de la medicina al estar centrada en la credibilidad de las instituciones y el prestigio de las facultades y sus egresados conlleva a la revisión de los discursos y representaciones documentales desde los criterios de reconocimiento oficial de títulos y procesos formativos, así como el prestigio y la credibilidad asociadas con la calidad formativa de los egresados, cuyas continuidades han sido reafirmadas por los procesos recientes de gestión y expedición de la "certificación de alta calidad" para los programas de medicina por parte del Ministerio de Educación Nacional.

Esa metodología de análisis historiográfico convoca a los investigadores a estudiar el devenir de profesiones como la medicina, la cirugía o la farmacia desde la perspectiva del reconocimiento, legitimización y legalización ante el Estado de los programas de formación profesional desde sus orígenes como parte de las reglas impuestas por los regímenes virreinal, presidencial y ministerial. De tal modo, las prácticas de formación y los criterios de licenciamiento y regulación requieren ser interpretados de forma diferente si se hace referencia a las facultades virreinales, las academias republicanas, y recientemente, al ser delegadas a la perspectiva interinstitucional de agremiaciones como Ascofame o la acción interuniversitaria de los pares evaluadores a nombre del Consejo Nacional de Acreditación.

Con el apogeo de los procesos de acreditación nacional e internacional de los programas de medicina a partir de 1994, los grandes relatos nacionales sobre médicos, facultades o instituciones médicas que beneficiaron y transformaron el país, así como las representaciones históricas regionales o locales sobre la lucha contra las endemias y epidemias regionales, han sido gradualmente sustituidos por las perspectivas del ser médico y el hacer medicina promovidas por cada institución de educación superior.

Representaciones del devenir para la autorreflexión y la autoevaluación entre los integrantes de cada comunidad educativa, las cuales facilitan a su vez el reconocimiento y valoración de su credibilidad y prestigio por parte de los pares evaluadores de otras facultades universitarias. Con lo cual, los relatos históricos acerca de la medicina tienden a exaltar las acciones colectivas y de cooperación interinstitucional que permiten alcanzar metas institucionales en extensión e 
investigación, así como examinan y contrastan los planes de desarrollo que atendiendo preceptos internacionales, nacionales y gremiales permiten evidenciar los resultados o proyecciones en la formación y profesionalización de los médicos colombianos.

\section{Bibliografía}

\section{Fuentes Primarias}

\section{Documentos}

Giraldo, Diego. Memorias para la historia de la Asociación Colombiana de Facultades de Medicina Ascofame. Bogotá: Ascofame, 2009.

Mutis, José Celestino. "Copia del Informe sobre el estado de la medicina, cirugía y farmacia del Nuevo Reino de Granada” (1801). Biblioteca Nacional de Colombia. Folios 98-106.

\section{Leyes}

Corte Constitucional de Colombia. Expediente D-486, Sentencia C-377/94 que declara exequible la ley 14 de 1962. http:/www.secretariasenado.gov.co/senado/ basedoc/c-377_1994.html.

República de Colombia. Ley 14 de 1962 (abril 28) por la cual se dictan normas relativas al ejercicio de la medicina y cirugía. https://www.mineducacion.gov. co/1621/articles-103807_archivo_pdf.pdf.

\section{Fuentes Secundarias}

\section{Artículos de revistas}

Miranda Canal, Néstor. "Apuntes para la historia de la medicina en Colombia". Ciencia, Tecnología y Desarrollo 8. 1-4 (1984): 136-147.

Miranda Canal, Néstor. "La medicina en Colombia. De la influencia francesa a la norteamericana". Credencial Historia, 1992. http://www.banrepcultural.org/ biblioteca-virtual/credencial-historia/numero-29/la-medicina-en-colombia.

Miranda Canal, Néstor. "La medicina en Colombia. De la influencia francesa a la norteamericana". Credencial Historia. 1992. http://www.banrepcultural.org/ biblioteca-virtual/credencial-historia/numero-29/la-medicina-en-colombia.

Patiño, José. “Abraham Flexner y el Flexnerismo. Fundamento imperecedero de la Educación Médica Moderna”. Revista de la Academia Nacional de Medicina Colombia 20. 2 (1998): 6-14. 
Medicina en Colombia. Profesión mediada por preceptos externos y prestigios internos...

Pérez Pinzón, Luis Rubén. "La lepra y los lazaretos en Santander. Discapacidad clínico-hospitalaria y minusvalía socio-cultural". Revista Salud UIS 37. 22 (2005):141-151.

Serpa-Flórez, Roberto. "Apuntes para la historia de la medicina. Santander y la UIS". Médicas UIS Revista de los estudiantes de medicina de la Universidad Industrial de Santander 20. 2 (2007): 157-167.

Vargas-Mantilla, Mónica. "Revisión de estrategias de turismo de salud e identificación de aportes para Santander, Colombia”. MedUNAB 20. 3(2017-2018):349-361.

\section{Libros}

Álvarez, Tiberio. Escuela de medicina de la Universidad de Antioquia: ciencia y presencia en la historia, 1871-2016. Medellín: Universidad de Antioquia, 2017.

Alzate, Adriana. Los oficios médicos del sabio: contribución al estudio del pensamiento higienista de José Celestino Mutis. Medellín: Universidad de Antioquia, 1999.

Bonilla Naar, Alfonso. Historia de la medicina tropical: parasitología e higiene en Colombia, datos bibliográficos correspondientes a 113 años de labores colombianas (1830-1943). Bogotá: Cromos, 1944.

Eslava, Juan Carlos. Facultad de medicina: su historia. Bogotá: Universidad de los Andes, 2018.

García, Mónica. Entre climas y bacterias: el saber sobre la enfermedad en Colombia, siglo XIX. Bogotá: Universidad del Rosario, 2016.

Garzón, Juan. Etnodesarrollo y medicina indígena ecológica. Bogotá: Ministerio de Salud, 1980.

Ibáñez, Pedro. Memorias para la historia de la medicina en Santa Fé de Bogotá. Bogotá: Universidad Nacional de Colombia, 1967.

Martínez, Abel. El Lazareto de Boyacá: lepra, medicina, iglesia y estado 1869-1916. Tunja: Universidad Pedagógica y Tecnológica de Colombia, 2006.

Noguera, Carlos. Medicina y política: discurso médico y prácticas higiénicas durante la primera mitad del siglo XX en Colombia. Medellín: Eafit, 2003.

Obregón, Diana. Batallas contra la lepra: estado, medicina y ciencias en Colombia. Bogotá: Banco de la República, 2002.

Pérez Pinzón, Luis Rubén, ed. Beneficencia, Higiene y Salud Pública en Colombia: La experiencia médico-sanitaria en Santander. Siglos XIX y XX. Trabajos de grado de la Escuela de Historia de la Universidad Industrial de Santander asociados 
con la línea de investigación en Historia de la Salud Pública y la enfermedad. Bucaramanga: UIS, 2013.

Pérez Pinzón, Luis Rubén. Historia de la Salubridad en Santander. Bucaramanga: Luis Pérez, 2015.

Pontificia Universidad Javeriana. Facultad de medicina 75 años entregando el corazón. Bogotá: Universidad Javeriana, 2017.

Quevedo, Emilio. Historia de la medicina en Colombia. Bogotá: Grupo Editorial Norma, 2007.

Téllez, Jairo. Maestría en toxicología: Once años de historia. Bogotá: Universidad Nacional de Colombia, 2011.

Zubiría, Roberto de. Antonio Vargas Reyes y la Medicina del Siglo XIX en Colombia. Bogotá: Academia Nacional de Medicina, 2002.

\section{Documentos, ponencias, tesis y otros}

Universidad Autónoma de Bucaramanga (Unab). Proyecto de investigación E89003: Contexto histórico de los programas de Medicina en Colombia». Bucaramanga: Dirección de Investigaciones de la Universidad Autónoma de Bucaramanga, 2019.

\section{Publicaciones en Internet}

Consejo Nacional de Acreditación (CNA) Conozca el CNA. https://www.cna.gov. co/1741/article-186382.html 